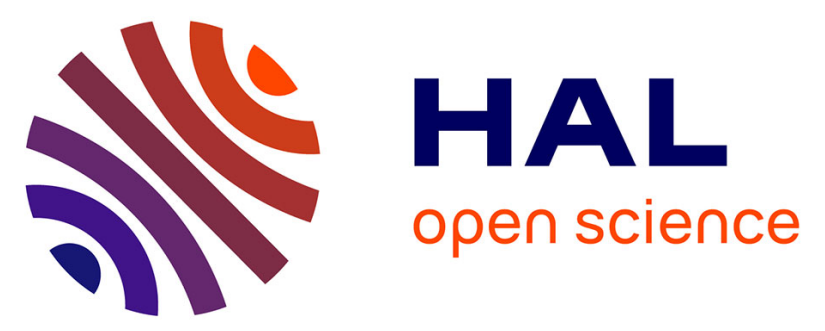

\title{
The Markowitz Model of Utility supplemented with a small degree of Probability Distortion as an explanation of Outcomes of Allais Experiments over Large and Small Payoffs and Gambling on Unlikely Outcomes.
}

David Peel

\section{- To cite this version:}

David Peel. The Markowitz Model of Utility supplemented with a small degree of Probability Distortion as an explanation of Outcomes of Allais Experiments over Large and Small Payoffs and Gambling on Unlikely Outcomes.. Applied Economics, 2008, 40 (01), pp.17-26. 10.1080/00036840701728781. hal-00582280

\section{HAL Id: hal-00582280 \\ https://hal.science/hal-00582280}

Submitted on 1 Apr 2011

HAL is a multi-disciplinary open access archive for the deposit and dissemination of scientific research documents, whether they are published or not. The documents may come from teaching and research institutions in France or abroad, or from public or private research centers.
L'archive ouverte pluridisciplinaire HAL, est destinée au dépôt et à la diffusion de documents scientifiques de niveau recherche, publiés ou non, émanant des établissements d'enseignement et de recherche français ou étrangers, des laboratoires publics ou privés. 


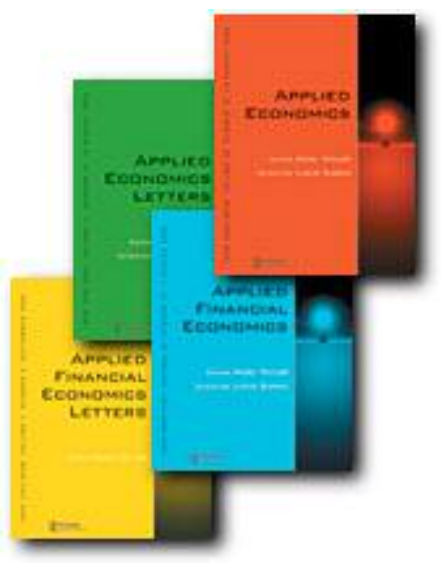

The Markowitz Model of Utility supplemented with a small degree of Probability Distortion as an explanation of Outcomes of Allais Experiments over Large and Small Payoffs and Gambling on Unlikely Outcomes.

\begin{tabular}{|r|l|}
\hline Journal: & Applied Economics \\
\hline Manuscript ID: & APE-07-0720 \\
\hline Journal Selection: & Applied Economics \\
\hline Author: & 05-Oct-2007 \\
\hline Complete List of Authors: & Peel, David; University of Lancaster, Economics \\
\hline JEL Code: & $\begin{array}{l}\text { C72 - Noncooperative Games \&lt; C7 - Game Theory and } \\
\text { Bargaining Theory \&lt; C - Mathematical and Quantitative Methods, } \\
\text { C92 - Laboratory, Group Behavior \&lt; C9 - Design of Experiments } \\
\text { \&lt; C - Mathematical and Quantitative Methods, D84 - } \\
\text { Expectations/Speculations \&lt; D8 - Information and Uncertainty } \\
\text { \&lt; D - Microeconomics }\end{array}$ \\
\hline Keywords: & Allais Paradox, Markowitz model of Utility \\
\hline
\end{tabular}

\section{(5) ScholaroNE \\ Manuscript Central}




\begin{abstract}
The Markowitz Model of Utility supplemented with a small degree of Probability Distortion as an explanation of Outcomes of Allais Experiments over Large and Small Payoffs and Gambling on Unlikely Outcomes.
\end{abstract}

We show that in principal only a small degree of probability distortion is necessary for agents to exhibit the Allais paradox. We also show that the choices observed in the Allais experiments employing small real payoffs cannot be explained by Cumulative Prospect Theory without the assumption of low degrees of probability distortion that rule out gambling at unfair odds on all but the most extreme longshots in $\mathrm{CPT}$.

Given these points we show that the Markowitz model of utility supplemented by a small degree of probability distortion can explain the majority choices involved Allais experiments and other experiments as well as gambling at actuarially unfair odds.

Keywords: Allais Paradox, Markowitz model of Utility, Cumulative Prospect Theory;; Gambling.

JEL classification: C72; C92; D80; D84 
The Markowitz Model of Utility supplemented with a small degree of Probability Distortion as an explanation of Outcomes of Allais Experiments over Large and Small Payoffs and Gambling on Unlikely Outcomes.

D.A.Peel*, Zhang, Jie* and D.Law**

*University of Lancaster

**University of Bangor

\section{Introduction}

In a seminal paper Markowitz (1952) proposed a new model of utility. Unlike in standard expected utility theory he assumed that from agents customary or normal level of wealth the agent was initially risk-loving then risk-averse over gains whilst initially risk-adverse then risk-seeking over losses. Though perhaps not widely appreciated the agent was also assumed to be loss averse. ${ }^{1}$ Apart from explaining simultaneous gambling and insurance the Markowitz model can also explain a variety of experimental evidence not consistent with standard expected utility theory. ${ }^{2}$

\footnotetext{
${ }^{1}$ Markowitz writes, "Generally people avoid symmetric bets. This suggests that the curve falls faster to the left of the origin than it rises to the right. We may assume that $|\mathrm{U}(-\mathrm{X})|>\mathrm{U}(\mathrm{X}), \mathrm{X}>0$ where $\mathrm{X}=0$ is customary wealth. " (pp154-155)". His diagram did not appear to exhibit this feature but the text $\mathrm{p}(155)$ and discussion makes it very clear that he assumes loss aversion.

2 This is because often the experimental evidence that conflicts with standard expected utility is explicable in terms of reference point effects or loss aversion and not probability distortion per-se. The Markowitz model through changes in the reference point, due to an increase in wealth, can explain the apparent preference of some agents for segregated gains reported by Thaler (1985, p. 203). The reference point effect can also explain why agents might turn down one gamble such as lose $\$ 100$ or win $\$ 150$ with win-probability 0.5 , but accept a sequence of $\mathrm{N}$ such bets, say,
} 
However important experimental evidence that the Markowitz model cannot explain is the Allais paradox, (see e.g. Allais (1953)). As is well known resolving this paradox requires that agents' subjective probabilities differ from objective probabilities. In the Markowitz model they are assumed equal.

Cumulative Prospect Theory of Kahneman and Tversky (1979) and Tversky and Kahnerman (1992) (KT) is now perhaps become the major alternative to expected utility theory having superseded Markowitz's model. ${ }^{3}$ Cumulative Prospect Theory (CPT) embodies the reference point hypothesis of Markowitz but restricts preferences to be solely risk-averse over gains and solely risk-loving over loses. KT also assume loss aversion but suggest it is of higher order of magnitude ${ }^{4}$ over small stakes than that that Markowitz would accept. ${ }^{5}$ To explain both the Allais paradox over large hypothetical returns and gambling on actuarially unfair outcomes KT assume that the probabilities of events are subjectively distorted by agents, via an inverted s-shaped probability weighting function so that small probabilities are over-estimated and large probabilities are understated. The probabilities are assigned to outcomes employing a

$\mathrm{N}=100$. As shown by Samuelson (1963) such behaviour is inconsistent with standard expected utility theory

${ }^{3}$ There are 193 citations to the Markowitz model in Google scholar (nov2006). This compares to 4625 to the KT 1979 paper and 1136 to their 1992 paper.

${ }^{4}$ In particular, the function is postulated to fall roughly twice as fast over losses as it rises over gains, exhibiting diminishing sensitivity as the marginal impact of losses or gains diminishes with distance from the reference point [see e.g. Tversky and Kahneman (1992)].

${ }^{5}$ He writes, "for very small symmetric bets the loss in utility from the bet is negligible and is compensated for by the "fun of participation". 
similar cumulative weighting function to that developed by Quiggin. ${ }^{6} \mathrm{CPT}$ is in principle able to explain the Allais paradox, a variety of other experimental evidence inconsistent with standard expected utility theory as well as gambling at actuarially unfair odds. However it is now known from analysis by Neilson and Stowe (2002) that power value functions ${ }^{7}$, assumed by KT in their parametric specification, cannot explain with the same parameter values both the Allais paradox over large returns and gambling over unlikely outcomes. Neilson and Stowe (2002), state that the most obvious conclusion of their work is that alternative functional forms are needed. ${ }^{8}$

\footnotetext{
${ }^{6}$ Note that if all outcomes are losses, the cumulative prospect preference function in (2) is identical to the rank-dependent expected utility preference function (e.g. Quiggin (1993)). Both apply the probability weighting function to the probability of the lowest outcome first. If all outcomes are gains the preference function in (1) differs from the rank dependent expected utility preference function by applying the weighting function to the probability of the highest outcome first.

${ }^{7}$ This conflicts with Markowitz who assumed bounded value functions. He wrote “ to avoid the famous St.Petersburg Paradox, or its generalization by Cramer, I assume that the utility function is bounded from above. For analogous reasons I assume it to be bounded from below." (p154)
}

${ }^{8}$ Neilson and Stowe endeavoured to explain the Allais paradox in an experiment involving millions. It is known from the celebrated results of Rabin (2000) that a utility function calibrated for low-stakes gambles implies unreasonable behaviour for high-stakes gambles, and vice-versa. Because their experiments involved only gains the same results will hold for cumulative prospect theory preferences. However, Neilson and Stowe also show that parameter combinations that are compatible with choices expressed in gambles with small monetary outcomes are also inconsistent with parameter values that imply "reasonable" threshold probabilities between gambling and insurance. 
A recent Allais experiment of List and Haigh (2005), using small real stakes, reports statistical significance of the Allais paradox in responses from both professional traders and students. However the majority of professional traders or students choose the risky option in both Allais questions so that the majority response does not reveal the Allais paradox. The choice patterns observed in the List and Haigh experiments is a common, though not universal finding, in Allais experiments involving small real stakes where often the choices do not reveal the Allais paradox. E.g.Conlisk (1989), Harrison (1994) and Burke et al. (1996) and also Ballinger et al. (1997), Battalio etal. (1990) Bernasconoi (1994), Camerer (1989), Kagel et al. (1990), Starmer and Sugden (1989) and $\mathrm{Wu}$ and Gonzalez (1996).

Choice of the risky options in the Allais experiments employing small real stakes contrasts with choices in the Allais experiments involving large, hypothetical, stakes. In these experiments the great majority of agents choose the certain outcome in one of the two questions (see e.g. Tversky and Kahneman (1992)). Accepting the validity of these hypothetical experiments we can make two points. First if the differing choices in Allais experiments employing small and larger stakes are to have a consistent choice theoretic explanation then, ceteris paribus, the power specification of the value function is invalid since the choice pattern is dependent on the size of the payoffs. ${ }^{9}$

\footnotetext{
${ }^{9}$ The recent empirical results of Holt and Laury are also particularly important in this context. They use real payoffs as well as hypothetical payoffs and find that risk aversion increases sharply as payoffs are scaled up as agents choose between a "safer" and "more risky" gamble. Both sets of experiments suggest that that increases in payoff levels increase risk aversion. With a power value function this would not occur. Since these experiments use small stakes the issue is not about the validity of the power function as an approximation over large or small stakes. We also note that some early experimental evidence, e.g. Markowitz (1952), Biswanger (1980) and Hershey and Shoemaker (1980) is also inconsistent with a power value
} 
Second agents may make choices consistent with the expected utility model even though they may suffer from probability distortion. Probability distortion is a necessary condition to exhibit the Allais paradox but not sufficient. This point has not apparently been fully appreciated in the literature. We show why in Allais experiments employing small the relative returns employed in components of the gamble will be expected to elicit preferences that display very different evidence for the paradox even when agents are assumed to exhibit the same degree of probability distortion.

The question arises as to the degree of probability distortion that is required to explain the preferences exhibited by agents in the Allais paradox over small and large stakes. In fact, the degree of probability distortion required to explain the Allais paradox can, as we show, be epsilon small. However we also show that the degree of probability distortion required in the $\mathrm{KT}$ model to induce agents to act as if risk-seeking, and thus engage in actuarially unfair gambles on long shots, translates into subjective expected

function. In these experiments the probabilities, in a sequence of gambles, are kept fixed as agents choose between a gamble and its certainty equivalent. Choices change significantly with size of payoff. Finally we note some theoretical objections to the power assumption. Blavatsky (2005) shows that the Kahneman-Tversky parameterization cannot resolve the St. Petersburg paradox unless the power coefficient of the utility function is less than that of the probability weighting function. However, this implies that the agent cannot exhibit risk-loving behavior and so gamble. Also the agent becomes infinitely gain loving over small enough stakes violating the loss aversion assumption, see e.g. Cain et al (2005) and Köbberling and Wakker (2004). 
rates of return that can run into hundreds of percent. Regardless of ones view of learning these sorts of subjective return appear too large to be systematic. Even assuming a small degree of probability distortion- in the third decimal point- we show that the subjective expected returns differ from the objective by a few percent.

Given these points we illustrate with a parametric specification how the Markowitz model, supplemented with a small degree of probability distortion, is able to parsimoniously explain, unlike CPT, majority choices in both experimental evidence such as the Allais paradox, other important experiments such as Holt and Laury (2002) also involving real stakes, as well as gambling at actuarially unfair odds.

The rest of the paper is structured as follows. Our analysis is set out in section 1 and the final section offers our conclusions.

\section{Section1}

We assume that the value function over gains, $U G$, is given by the expo-power function of Saha (1993).

$$
\mathrm{UG}=1-\mathrm{e}^{-\mathrm{rG}^{\mathrm{n}}}
$$

where $\mathrm{G}$ is gains and $\mathrm{r}, \mathrm{n}$ are positive constants.

For $\mathrm{n} \leq 1$ the agent is everywhere risk-averse over gains as postulated by KT. For $\mathrm{n}>1$ the agent is risk-loving (risk-verse, $<$, risk-neutral $=$ ) as $\frac{\mathrm{n}-1}{\mathrm{rn}}>\mathrm{G}^{\mathrm{n}} \cdot{ }^{10}$

\footnotetext{
${ }^{10}$ Many studies assume that the value function takes the form assumed by KT and given this solve for the value of the weighting function parameters and value of the probability distortion parameters consistent with their choices in experiments. (see e.g. Stott (2005) for a comprehensive survey). Where the KT form of value function
} 
The expo-power function has the convenient property that as $r \rightarrow 0$ the function approximates the power value function, $\mathrm{G}^{\mathrm{n}}$.

We assume in our examples that the probability weighting function, $w(p)$, has the form employed by KT and is given by

$$
\mathrm{w}(\mathrm{p})=\frac{\mathrm{p}^{\delta}}{\left[\mathrm{p}^{\delta}+(1-\mathrm{p})^{\delta}\right]^{\frac{1}{\delta}}}
$$

where $\mathrm{p}$ is the objective probability and $\delta$ is a positive constant less than unity ${ }^{11}$.

We assume that probability weighting over gains and losses is that of CPT.

Consider the two standard forms of the Allais experiments. In experiment one agents are offered the choice between the alternatives $\mathrm{A}$ and $\mathrm{A}^{*}$ and the alternatives $\mathrm{B}$ and $\mathrm{B}^{*}$ where

A: a certain $\$ X$. or $A^{*}: \$ X$ with probability $\mathrm{p}_{1}, \$ Y$ with probability $\mathrm{p}_{2}$ and $\$ 0$ with probability $1-\mathrm{p}_{1}-\mathrm{p}_{2}$.

B: $\$ X$ with probability $1-\mathrm{p}_{1}$ or $\mathrm{B}^{*}: \$ Y$ with probability $\mathrm{p}_{2}$.

For instance Tversky and Kahneman (1992) set $X=2400$. $Y=2500, p_{1}=0.66, p_{2}=0.33$.

List and Haigh (2005) set $\mathrm{X}=7$. $\mathrm{Y}=10, \mathrm{p}_{1}=0.75, \mathrm{p}_{2 .}=0.25$.

is not assumed a number of studies such as Levy and Levy $(2001,2002)$,Pennings and Smidts $(2000,2003)$ report empirical evidence that many agents do not have the shape of value function conjectured by $\mathrm{K}$ and $\mathrm{T}$. We discuss in the paper some experiments which can, in principle, provide tests between the competing value functions. Much of the empirical evidence is "observationally equivalent".

11 Employing the weighting function of Prelec (1998) makes no qualitative difference to the results. 
and Conlisk (1989) sets $\mathrm{X}=5 . \mathrm{Y}=25, \mathrm{p}_{1}=0.89, \mathrm{p}_{2 .}=0.1$.

In experiment two agents are offered the choice between the alternatives $\mathrm{C}$ and $\mathrm{C}^{*}$ and $\mathrm{D}$ and $\mathrm{D}^{*}$ where

C: a certain $\$ \mathrm{G}$ or $\mathrm{C}^{*} \$ \mathrm{H}$ with probability $\mathrm{p}_{3}$

D: $\$ \mathrm{G}$ with probability $p_{4}=\frac{1}{h}$ or $\mathrm{D}^{*} \$ \mathrm{H}$ with probability, $\frac{p_{3}}{h}$

were $\mathrm{h}$ is typically set equal to 4 as in for example Tversky and Kahneman (1992) with $\mathrm{G}=3000, \mathrm{H}=4000$ and $\mathrm{p}_{3}=0.8$.

Under Cumulative Prospect Theory the choice between A and A* is given by

$\mathrm{U}(\mathrm{X})$ or $\mathrm{w}\left(\mathrm{p}_{2}\right) \mathrm{U}(\mathrm{Y})+\left[\mathrm{w}\left(\mathrm{p}_{2}+\mathrm{p}_{1}\right)-\mathrm{w}\left(\mathrm{p}_{2}\right)\right] \mathrm{U}(\mathrm{X})$

Recalling that $\mathrm{Y}>\mathrm{X}$

and between $B$ and $B *$ by

$\mathrm{w}\left(1-\mathrm{p}_{1}\right) \mathrm{U}(\mathrm{X})$ or $\mathrm{w}\left(\mathrm{p}_{2}\right) \mathrm{U}(\mathrm{Y})$

That between $\mathrm{C}$ and $\mathrm{C}^{*}$ by

$\mathrm{U}(\mathrm{G})$ or $\mathrm{w}\left(\mathrm{p}_{3}\right) \mathrm{U}(\mathrm{H})$

and that between $\mathrm{D}$ and $\mathrm{D*}$ by

$w\left(\frac{1}{h}\right) U(G)$ or $w\left(\frac{p_{3}}{h}\right) U(H)$

The typical majority choice patterns observed in experiment one when payoffs are large is $\mathrm{A}>\mathrm{A}^{*}$ and $\mathrm{B}<\mathrm{B}^{*}$ and for small payoffs $\mathrm{A}<\mathrm{A}^{*}$ and $\mathrm{B}<\mathrm{B}^{*}$. The typical choices observed for large payoffs in experiment two are $\mathrm{C}>\mathrm{C}^{*}$ and $\mathrm{D}<\mathrm{D}^{*}$.

Consistent choice under expected utility requires the choice patterns $A>A^{*}$ and $B>B^{*}$ or $\mathrm{A}<\mathrm{A}^{*}$ and $\mathrm{B}<\mathrm{B} *$ in experiment one and $\mathrm{C}>\mathrm{C}^{*}$ and $\mathrm{D}>\mathrm{D} *$ or $\mathrm{C}<\mathrm{C}^{*}$ and $\mathrm{D}<\mathrm{D} *$ in experiment two.

Manipulation of the choice pattern $\mathrm{A}>\mathrm{A}^{*}$ and $\mathrm{B}<\mathrm{B}^{*}$ informs us that a necessary condition for the Allais paradox choice pattern $\mathrm{A}>\mathrm{A} *$ and $\mathrm{B}<\mathrm{B} *$ is that 
$1-\mathrm{w}\left(\mathrm{p}_{1}+\mathrm{p}_{2}\right)>\mathrm{w}\left(1-\mathrm{p}_{1}\right)-\mathrm{w}\left(\mathrm{p}_{2}\right)$

which, for example, for the Conlisk (1989) experiment is

$1-\mathrm{w}(0.99)>\mathrm{W}(0.11)-\mathrm{w}(0.1)$

Substitution of the weighting function (2) into (7) reveals that any value of the distortion parameter $\delta$ less than unity is consistent with (7). Consequently epsilon probability distortion is consistent with the Allais paradox preferences $A>A^{*}$ and $B<$ $B^{*}$. Substitution also reveals that this is the case for the violation $C>C^{*}$ and $D<D^{*}$. However we stress this is only a necessary condition.

Consider the comparison between $\mathrm{A}$ and $\mathrm{A}^{*}$ using the expo-power function (1). We choose between

$1-\mathrm{e}^{-r X^{n}}$ or $\mathrm{w}\left(\mathrm{p}_{2}\right)\left(1-\mathrm{e}^{-\mathrm{r} \lambda^{\mathrm{n}} X^{\mathrm{n}}}\right)+\left[\mathrm{w}\left(\mathrm{p}_{2}+\mathrm{p}_{1}\right)-\mathrm{w}\left(\mathrm{p}_{2}\right)\right]\left(1-\mathrm{e}^{-\mathrm{r} X^{\mathrm{n}}}\right)$

where $\mathrm{Y} \equiv \lambda \mathrm{X}$

as we let payoff size $\mathrm{X} \rightarrow 0$ (or $\mathrm{r} \rightarrow 0$ ) by L'Hopitals rule we obtain from (8)

that the choice is given by the same relationship as with a power specification of the value function, namely a choice between

$$
1 \text { or } \mathrm{w}\left(\mathrm{p}_{2}\right)\left(\lambda^{\mathrm{n}}-1\right)+\mathrm{w}\left(\mathrm{p}_{2}+\mathrm{p}_{1}\right)
$$

Similar manipulation for choices $\mathrm{B}$ or $\mathrm{B}^{*}$ gives

$\mathrm{w}\left(1-\mathrm{p}_{1}\right)$ or $\mathrm{w}\left(\mathrm{p}_{2}\right) \lambda^{\mathrm{n}}$

If we let payoff size become very large then the choice of $\mathrm{A}$ or $\mathrm{A}^{*}$ is the choice between 1 or $\mathrm{w}\left(\mathrm{p}_{2}+\mathrm{p}_{1}\right)$ and between $\mathrm{B}$ and $\mathrm{B}^{*}$ byw $\left(1-\mathrm{p}_{1}\right)$ or $\mathrm{w}\left(\mathrm{p}_{2}\right)$. Consequently for large enough payoffs we would choose A and B and act as an expected utility maximiser regardless of the degree of probability distortion. 
We note from (9) the important point that, ceteris paribus, the larger $\lambda$ the more likely the agent to make the choices $\mathrm{A}^{*}$ and $\mathrm{B}^{*}$. The Conlisk experiment had a value of $\lambda$ of 5 whilst that of List and Haigh had a value of $\lambda$ of $\frac{10}{7}$.

In Table 1 we tabulate the values of the distortion parameter required to make the choice $\mathrm{A}>\mathrm{A}^{*}$ and $\mathrm{B}>\mathrm{B}^{*}$ for various values of $\mathrm{n}$ assuming a power value function.

We can deduce from Table1 that in List and Haigh's experiments, given by 1a and 1b, if all the traders had a power utility parameter of $n=0.88$ and a distortion parameter of $\delta=0.835$ then they would choose $\mathrm{A}^{*}$ and $\mathrm{B}^{*}$ and behave as expected utility maximisers. Suppose students had the same probability distortion parameter of $\delta=0.835$ but were more risk-averse with $n=0.5$. They would choose $A>A^{*}$ and $B^{*}>B$ and exhibit the Allais paradox. Consequently List and Haigh's experimental outcomes could reflect the fact that some students are more risk-averse over gains than traders not that they suffer greater probability distortion.

One other interesting feature of their experiment is that the choice of $A^{*}$ by many respondents implies a higher value of $\delta$ than postulated by KT and one which will mitigate against gambling at actuarially unfair odd as we show below.

If we consider the Conlisk experiment, $2 \mathrm{a}$ and $2 \mathrm{~b}$ we observe that in order not to make the choices $\mathrm{A}^{*}$ and $\mathrm{B}^{*}$ respondents would have to exhibit extreme probability distortion with $\delta<0.44$.

In Table 2 where we report some values of $r, n$ and $\delta$ for which an agent with the expopower value function would make the majority response in six experiments. These are the three experiments above plus the Allais experiments involving the choices between $\mathrm{C}$ and $\mathrm{C}^{*}$ and $\mathrm{D}$ and $\mathrm{D}^{*}$, also set out above, and in addition two of the important experiments of Holt and Laury (2002) who used real stakes. 
In the Holt and Laury experiments agents choose between the "safer" gamble, M: which is $\$ 2 \mathrm{x}$ with probability $\mathrm{p}$ and $\$ 1.6 \mathrm{x}$ with probability $1-\mathrm{p}$ and the "more risky gamble $\mathrm{N}$ : which is $\$ 3.85 \mathrm{x}$ with probability $\mathrm{p}$ and $\$ 0.1 \mathrm{x}$ with probability $1-\mathrm{p} . \mathrm{p}$ takes values between 0.1 and $1 . \mathrm{x}$ is set at 1 or 20 in the experiments we consider. Their experiments suggest that the increases in payoff levels increase risk aversion with the switch between $\mathrm{M}$ and $\mathrm{N}$ occurring at different probabilities. With a power value function this switch could not occur. Since these experiments use relatively small stakes the issue is not simply about the validity of the power function as an approximation to utility over large or small stakes. Whilst Holt and Laury did not investigate their outcomes from the perspective on non-expected utility we can employ their carefully crafted experiments in order to calibrate our non-expected model.

The important point that emerges from Table 2 is that an agent with an expo-power value function with $r>0.00007$ from experiment $4 \mathrm{a}$ and $\mathrm{r}<10.00016$ from experiment $3 b$, and $\delta=0.95$ and $n=1.1$, so that it takes the Markowitz form, will make the majority responses observed in the six experiments. There may, of course, be other parameter combinations with even less probability distortion and the Markowitz form of value function, which can also explain the experimental evidence. However our example illustrates that the Markowitz model, with a much smaller degree of probability distortion than assumed by $\mathrm{KT}$, can be consistent with important experimental evidence. From an apriori perspective we think this important. It is apparently not widely appreciated how small differences between the objective and subjective probabilities imply large differences between the objective and subjective expected rate of returns of a gamble. 
We define the expected return, $\mu$, and the subjective expected return, $\mu^{\mathrm{s}}$, from a one unit gamble as respectively,

$\mu \equiv \mathrm{po}-(1-\mathrm{p})$

and

$\mu^{\mathrm{s}} \equiv \mathrm{w}(\mathrm{p}) \mathrm{o}-\mathrm{w}(1-\mathrm{p})$

where $\mathrm{p}=$ objective win probability, $\mathrm{o}=$ odds and

$$
\mathrm{w}(\mathrm{p})=\frac{\mathrm{p}^{\delta}}{\left[\mathrm{p}^{\delta}+(1-\mathrm{p})^{\delta}\right]^{\frac{1}{\delta}}}, \mathrm{w}(1-\mathrm{p})=\frac{(1-\mathrm{p})^{\rho}}{\left[\mathrm{p}^{\rho}+(1-\mathrm{p})^{\rho}\right]^{\frac{1}{\rho}}}
$$

with $0<\delta \leq 1, \quad 0<\rho \leq 1$.

In Table 3 we tabulate some values of $\mu^{\mathrm{s}}, \mathrm{w}(\mathrm{p})$ and $\mathrm{w}(1-\mathrm{p})$ corresponding to values of $\mu$ and $p$ employing the values of $\delta$ and $\rho$ employed by Tversky and Kahneman (1992), namely $\delta=0.61, \rho=0.69$, as well as the higher values of $\delta=0.95, \rho=0.95$ suggested by our Markowitz calibration. We note that with the higher values of $\delta=0.95, \rho=0.95$ the subjective probability only differs from the objective probability in the third or fourth decimal point. Nevertheless the subjective and objective rates of return can differ by up to $25 \%$ in our examples. The values of the weighting function parameters over gains and losses assumed by Tversky and Kahneman imply positive subjected rates of return sometimes running into hundreds of percent for gambles with negative objective rates of return, for example exhibits 3 , 4, and 5. A subjective expected rate of return of 239.27 for betting on a number at roulette, as in exhibit 3 , when the true objective rate of return is -0.053 , seems apriori too high to be systematically tenable.

Of course because of the assumed risk-seeking segment of the value function, gambling at actuarially unfair odds can occur without probability distortion in the 
Markowitz model. The KT model requires substantial probability distortion in order to generate subjective expected rates of return to overcome the risk-aversion assumed over gains.

To illustrate this we consider the expected utility from a gamble.

Defining reference point utility as zero, expected utility in the Markowitz model with distortion or the KT model is given by

$$
\mathrm{Eu}=\mathrm{w}(\mathrm{p}) \mathrm{U}(\mathrm{so})-\mathrm{w}(1-\mathrm{p}) \mathrm{U}(\mathrm{s})
$$

where, $U(s o)$ is the value derived from a winning gamble, where $o$ are the odds and $s$ the stake. $U(s)$ is the disutility derived from a losing gamble.

Employing the expo-value function we have

$$
\mathrm{Eu}=\mathrm{w}(\mathrm{p})\left(1-\mathrm{e}^{-\beta \alpha(\mathrm{so})^{\mathrm{n}}}\right)-\mathrm{w}(1-\mathrm{p}) \mathrm{k}\left(1-\mathrm{e}^{-\alpha \mathrm{s}^{\mathrm{n}}}\right)
$$

where we set $r$ above in (1) as $r=\beta \alpha$ a convenient parameterization for the analysis below. $\beta, \alpha$ and $\mathrm{k}$ are constants and other terms are as defined earlier.

For the utility function in (14), the degree of loss aversion, (LA), is defined by the ratio of the utility gain to the utility loss from a symmetric gamble, given by

$$
\mathrm{LA}=\frac{\left(1-\mathrm{e}^{-\beta \alpha \mathrm{s}^{\mathrm{n}}}\right)}{\mathrm{k}\left(1-\mathrm{e}^{-\alpha \mathrm{s}^{\mathrm{n}}}\right)}
$$

As stake size approaches zero, the assumption of loss aversion requires that $\frac{\beta}{\mathrm{k}}<1$,

(by L'Hopital's Rule), and as it becomes large that $\frac{1}{\mathrm{k}}<1$. Consequently the degree of loss aversion varies between $\frac{\beta}{\mathrm{k}}$ and $\frac{1}{\mathrm{k}} \quad$ In order to ensure that $\frac{\partial L A}{\partial s} \leq 0$, so that the degree of loss aversion does not decrease with an increase in stake size we require 
that $\frac{d \frac{U^{r}(s)}{U^{l}(s)}}{d s}<0$, which for $\mathrm{LA}<1$, implies that $\frac{\partial U^{r}(s)}{\partial s}<\frac{\partial U^{l}(s)}{\partial s}$ for all s, which is consistent with the definition of loss aversion of Benartzi and Thaler (1995) and Köbberling and Wakker (2005)). For the expo-power function this implies the additional constraint that $\beta \geq 1$.

The parameter values we employ are $\beta=6.3, \mathrm{k}=10, \alpha=0.000071$ and $\mathrm{n}=1.1$

With these parameter values the Markowitz agent makes the majority choices in the experiments involving gains reported above. How does the agent behave over gambles involving potential losses? Calculation informs us that the agent is happy to gamble at some actuarially unfair odds. For instance the agent will

(a) Bet $\$ 1$ on a number at roulette wheel, objective $\mathrm{p}=\frac{1}{38}$, objective rate of return equal -0.05263 , bet $\$ 1$ on a horse with objective $\mathrm{p}=0.01$ and objective rate of return $>-0.18$, bet $\$ 1$ on a lottery ticket with objective $p=0.001$ and objective rate of return $>-0.38$.

In addition the agent will

(b) Bet $\$ 10$ at win probability, $p=0.5$ if she wins in excess of $\$ 15.23^{12}$

\footnotetext{
${ }^{12}$ We recognise that our parametric Markowitz specification is still subject to the Rabin criticism, (as originally applied to expected utility preferences). The level of risk aversion observed with respect to the small gamble ( turn down a win \$11 lose $\$ 10$ at $\mathrm{p}=0.5$ ) still leads to a high, though perhaps less absurd, level of risk aversion in that our agent would reject a win infinity lose in excess of $\$ 1513$ gamble at $p=0.5$ as opposed to infinity and $\$ 100$ if an expected utility maximiser. However, e.g. Safra and Segal (2006) have shown that Rabin's arguments apply to many non-expected utility theories.
} 
(c) Will not accept a bet of lose $\$ 100$ or win $\$ 150$ at win probability 0.5 , but will accept a sequence of two or more such bets. An outcome inconsistent with expected utility theory as shown by Samuelson (1963).

Cumulative prospect theory can, of course, also produce outcomes qualitatively similar to (a) to (c). However betting at actuarially unfair odds is rapidly curtailed as the degree of probability distortion is reduced. With the parameter values $\alpha=0$ and $\mathrm{n}=0.88, \mathrm{k}=2.25, \delta=0.61$ and $\rho=0.69$ we have the model set out in Tversky and Khanerman (1992). If we decrease the degree of probability distortion over gains and losses, so that $\delta=0.84$ and $\rho=0.85$, the agent will make the majority responses found in the List and Haigh experiment. However we now find that the agent will not accept any of the actuarially unfair gambles in (a) above and needs as a matter of fact to receive an objective expected rate of return of in excess of $103 \%$ to gamble at objective odds of $\mathrm{p}=0.01$ and in excess of $184 \%$ at objective $\mathrm{p}=0.001$.

\section{Conclusions}

We show that in principal only a small degree of probability distortion is necessary to exhibit the Allais paradox. Also that in Allais experiments involving small real payoffs, even when agents exhibit probability distortion, majority preferences will often not reveal the Allais paradox if relative payoff ratios in the different components of the small payoff experiment are large. We also show that the choices observed in the Allais experiments employing small real payoffs, such as List and Haigh, cannot be explained by CPT without the assumption of much lower degrees of probability distortion than usually assumed in that model. However lower degrees of probability 
distortion rule out gambling at unfair odds on all but the most extreme longshots in CPT.

Given the above points we conduct a similar exercise as that Nielson and Stowe (2002) and ask if a calibrated version of the Markowitz function can be consistent with the majority outcomes observed in number of experiments. We show that this is possible. The Markowitz model of utility, supplemented by a small degree of probability distortion, can explain the majority choices involved in some Allais experiments over large and small payoffs, the experiments of Holt and Laury as well as gambling at actuarially unfair odds ${ }^{13}$. Given that the subjective expected returns required to induce gambling on long shots in the KT model are, at least from our perspective, apriori, too high to be credible, we consider this a major advantage of the modified Markowitz model. ${ }^{14}$

\footnotetext{
${ }^{13}$ We are aware that a Fechner model of random errors as in e.g. Hey and Orme (1994) is potentially relevant in any particular experiment for explaining decisions between lotteries A and B that only differ by small amounts of utility. However our purpose here is to illustrate that the Markowitz model is able, with a small amount of probability distortion, to explain majority choices in a large number of experiments without recourse to, what appear to us, extreme assumptions about probability distortion.
}

${ }^{14}$ It is unclear whether Markowitz was aware of the Allais paradox or simply gave it little weight when he wrote his pioneering paper. It is perhaps interesting to speculate how different the future path of research would have been had he included epsilon probability distortion in his model. 
There are a number of other experiments that would offer potential for differentiating between CPT and the Markowiz model.

The first are Allais experiments employing real stakes in which the relative payoffs are closer together. Consistent choice of the risk-seeking alternatives in such experiments would imply, from the perspective of the KT model, that any probability distortion had to be minimal and consequently render the KT model unable to explain gambling at actuarially unfair odds.

A second set of experiments which deserve further study are those of Battalio et al (1990). They reported that the majority of their respondents displayed risk seeking behaviour in choices over gambles involving small real gains at probabilities of 0.5 This finding is not explicable in the KT framework since it contradicts the subcertainty principle used to explain the Allais paradox (see KT, 1979,pp281-282). Of course such an outcome can be consistent with a Markowitz specification ${ }^{15}$. Finally, as first pointed out by Cain et al (2003), the Markowitz model is consistent with the stylised properties of winning bets in the pari-mutuel pools to those obtained in the parallel bookmaking market whilst, as pointed out first by Paya et al (2005), the KT model is apparently not. ${ }^{16}$. I particular agents betting on odds on favourites on the Tote

\footnotetext{
${ }^{15}$ For instance the majority preferred $\$ 25$ with $p=0.5$ or $\$ 5$ with $p=0.5$ to a certain
} $\$ 15$. With our parameters the risky gamble is preferred if $\mathrm{r}<0.0048$., $\delta=0.95, n=1.1$.

${ }^{16}$ Gabriel and Marsden (1990) in an innovative analysis compared the returns to winning bets in the British Tote with those offered by bookmakers at starting prices. They reported the striking finding that tote returns to winning bets during the 1978 British horseracing season were higher at all bookmaker odds, on average, than those 
offered by bookmakers. As noted by Sauer (1998) this result calls for explanation. In fact it appears from subsequent analysis that the relationship between tote returns and bookmaker returns for winning gambles is more complicated than reported by Gabriel and Marsden. Tote pay outs for a unit stake appear higher than bookmakers for long shot winners with the reverse apparently the case for favored horses: see Blackburn and Pierson (1995), Cain et al (2001) and Peel and Law (2007). Contrary to the assumption of Gabriel and Marsden Tote and Bookmaker returns are not the same asset. As stressed by Cain et al (2003) bets on the Tote have uncertain payoffs whilst those with the bookmaker are essentially certain.

Jensen's inequality implies that $E U(G)>U(E G), E U(G)=U(E G)$ and $E U(G)<U(E G)$, as the agent is respectively risk loving, risk-neutral and risk-adverse over Gains, G.

As a consequence as pointed out by Cain et al (2003) because the Tote pay-out is uncertain, ex-ante, whilst bookmaker returns are essentially known, ex-ante, expected returns would be expected to be equal on average only if the representative punter is risk-neutral, an assumption implicit in Gabriel and Marsden's analysis. If the agent is assumed everywhere risk-averse over gains, as in the Cumulative prospect theory of Kahneman and Tversky, it would appear that ex-ante they must expect a higher return from betting on the Tote on either favorites or longshots. Since the empirical evidence shows that Bookmaker payouts are higher on average for favourites than those on Tote the model of KT cannot, apparently, explain this key empirical finding.

On the other hand the Markowitz model, as pointed out by Cain et al (2003), because of the assumed risk-seeking behavior over favorites and risk-aversion 
do not appear to be explicable in terms of the KT model so that they would appear to be prime agents for inclusion in experiments on risk-attitudes.

\section{References}

Allais, Maurice.1953. “Le Comportement de l'Homme Rationnel devant le Risque: Critique des Postulats ET Axiomes de 1'Ecole Américaine,” Econometrica 21, 503546.

Ballinger, T. Parker and Nathaniel T. Wilcox. (1997). "Decisions, error and heterogeneity" Economic Journal 107, 1090-05

over long-shots, would imply tote returns could be expected to be lower for favorites and vice-versa for long shots. 
Battalio, Raymond C, John C. Kagel, and K. Jiranyakul. 1990. "Testing Between Alternative Models of Choice Under Uncertainty: Some Initial Results," Journal of Risk and Uncertainty, 3: 25-50.

Bernasconi, Michele. (1994). "Nonlineal preference and two-stage lotteries: theories and evidence" Economic Journal 104, 54-70

Benartzi, Shlomo, and Richard H. Thaler. (1995), "Myopic Loss Aversion and the Equity Premium Puzzle,” Quarterly Journal of Economics 110, 73-92.

Binswanger, Hans. P.1981. "Attitudes Toward Risk: Theoretical Implications of an Experiment in Rural India,” Economic Journal, 91. 867-890.

Blavatsky, Pavlo R. 2005. "Back to the St. Petersburg Paradox?” Management Science, 51(4): 677-678.

Burke, Michael S, John R. Carter, Robert D. Gominiak and Daniel F. Ohl. 1996. “An Experimental Note on the Allais Paradox and Monetary Incentives," Empirical Economics, 21(6):617-632.

Cain, M.. Law, D. and Peel, D. (2001) 'The Incidence of Insider Trading in Betting Markets and the Gabriel and Marsden Anomaly', The Manchester School, 69, pp. $197-207$ 
Cain, M.. Peel, D.A. Law, D. (2003a) 'The Favourite-Longshot bias and the Gabriel and Marsden Anomaly: An Explanation Based on Utility Theory', in L. Vaughan Williams (ed.), The Economics of Gambling London: Routledge, pp. 2- 13

Cain, Michael, David Law and David A. Peel. (2005) "Cumulative Prospect Theory and Gambling" mimeo University of Lancaster.

Camerer, F. Colin. (1989). "An experimental test of several generalized utility theories." Journal of Risk and Uncertainty 2, 61-104

Camerer, Colin F, and Ho Teck-Hua .1994. "Violations of the betweeness axiom and nonlineraity in probability," Journal of Risk and Uncertainty, 8, 167-196.

Conlisk, John.1979. "Three Variants on the Allais Example," The American Economic Review, 79(3): 392-407.

Harrison, Glenn W.1994. "Expected Utility Theory and the Experimentalists, “Empirical Economics, 19, 223-253.

Harrison, Glenn W, and John A .List. 2004. "Field Experiments," Journal of Economic Literature, 42(4): 1013-1059. 
Hershey, John C, and Paul J.H. Shoemaker. 1980. "Prospect theory's reflection hypothesis: a critical examination", Organizational Behavior and Human Performance, 25, 395-418.

Hey J D and Orme C D (1994), "Investigating Generalisations of Expected Utility Theory Using Experimental Data”, Econometrica, 62, 1291-1326.

Holt, Charles A, and Susan K. Laury..2002. "Risk Aversion and Incentive Effects," American Economic Review, 92(5): 1644-1655.

Kachelmeier, Steven J, and Mohamed Shehata. 1992. "Examining Risk Preferences Under High Monetary Incentives: Experimental Evidence from the People's Republic of China," American Economic Review, 82(5):1120-1141.

Kahneman, Daniel, and Amos Tversky. 1979. "Prospect Theory: An Analysis of Decision under Risk," Econometrica, 2, 263-91.

Kagel, H. John, Don N. MacDonald and Raymond C. Battalio. (1990). "Tests of "Fanning Out" of Indifference Curves: Results from Animal and Human Experiments" American Economic Review 80, 912-921

Köbberling, Veronika, and Peter Wakker. (2005), “An Index of Loss Aversion,” Journal of Economic Theory, 122,119-131. 
Laury, Susan K, and Holt, Charles A. (2002) "Further Reflections on Prospect Theory," Working Paper, Department of Economics, Georgia State University, 2002; available at http://www.people.virginia.edu/ cah2k/reflect.pdf

Levy, Moshe. and Levy, Haim (2001) “ Testing for Risk Aversion: a Stochastic Dominance Approach”, Economics Letters, 71, 233-240.

Levy, Haim and Moshe Levy, (2002) "Experimental Test of The Prospect Theory Value Function" Organizational Behavior and Human Decision Processes, forthcoming.

List, John A,. and Haigh, Michael.2005. "A Simple Test of Expected Utility Theory Using Professional Traders," Proceedings of the National Academy of Science , 102(3): 945-948.

Markowitz, Harry, M. 1952 “The Utility of Wealth”, Journal of Political Economy, $56,151-154$.

Neilson, William, S. and Jill Stowe. 2002. "A Further Examination of Cumulative Prospect Theory Parameterizations", Journal of Risk and Uncertainty, 24, 31-46.

Paya, Ivan., Peel, David .A.,Law, David. And Peirson, John. 2005. Testing for Market Efficiency in Gambling Markets: Some observations and new Statistical Tests based on a Bootstrap Method chapter 17 pp346-365 in Information Efficiency in Financial and Betting Markets, ed by Williams, Leighton Vaughan. Cambridge University Press. 
Peel, David A, and Law, David (2007) "Non-Expected Utility Models and Heterogeneity in Risk Attitudes: Towards an Explanation of Gambling Outcomes for Individual and Markets". Mimeo University of Lancaster.

Penning, Joost, M. .E. and Smidts, Ale. (2000) “Assessing the Construct Validity of Risk Attitude", Management Science, Vol. 46, No. 10 (Oct., 2000), pp. 1337-1348

Penning, Joost, M. .E. and Smidts, Ale. (2003) “The Shape of Utility Functions and Organizational Behavior” Management Science, 49, 1251 - 1263

Peirson, J, and Blackburn, P. (2003) 'Betting at British Racecourses; A Comparison of the Efficiency of Betting with Bookmakers and at the Tote', in L. Vaughan Williams (ed_), The Economics Gambling. London and New York: Routledge. pp. $30-42$

Prelec, Drazen. 1998. “The Probability Weighting Function,” Econometrica 66, 497527.

Rabin, Mathew.2000. "Risk Aversion and Expected-Utility Theory: A Calibration Theorem", Econometrica, 68(5): 1281-1292.

Quiggin, John.1993. Generalized Expected Utility Theory: The Rank-Dependent Model, Kluwer Academic Publishers: Dordrecht. 
Safra, Z and Segal, U. 2006 “calibration Results for Non-Expected Utility Theories”, mimeo University of Tel-Aviv.

Saha, Atanu.1993. "Expo-Power Utility: A Flexible Form for Absolute and Relative Risk Aversion,” American Journal of Agricultural Economics, (75), 905-913.

Samuelson, Paul, .A. 1963."Risk and Uncertainty: A Fallacy of Large Numbers", Scientia, 153-158.

Sauer, Raymond D. (1998) 'The Economics of Wagering Markets', Journal of Economic Literature, 36, pp. 202164

Starmer, Chris and Robert Sugden. (1989). "Probability and juxtaposition effects: An experimental investigation of the common ratio effect." Journal of Risk and Uncertainty 2, 159-178

Stott, Henery P. (2006) “Cumulative Prospect Theory's Functional Menagerie",Jpournal of Risk and Uncertainty,2,101-130.

Thaler, Richard..1985."Mental Accounting and Consumer Choice”, Marketing Science, 4, 199-214.

Tversky, Amos, and Daniel Kahneman. 1992. "Advances in Prospect Theory: Cumulative Representation of Uncertainty," Journal of Risk and Uncertainty, 5, 297323.

Wu, George, and Richard Gonzalez.1996. "Curvature of the Probability Weighting Function," Management Science 42, 1676-1690. 
Table1: Values consistent with choices in Allais Paradox of $A>A^{*}, B>B *$

\begin{tabular}{|c|c|c|c|c|}
\hline No.. & Experiment & $\delta, \mathrm{n}$ & $\delta, \mathrm{n}$ & $\delta, \mathrm{n}$ \\
\hline $1 \mathrm{a}$ & $\begin{array}{l}\text { A: } 7 \text { or } \\
A^{*}: 0.2 \text { of } 10,0.75 \text { of } 7 \text { and } 0.05 \text { of zero }\end{array}$ & $\begin{array}{l}\mathrm{n}=0.5 \\
\delta \text { any }\end{array}$ & $\begin{array}{l}\mathrm{n}=0.88 \\
\delta<0.832\end{array}$ & $\begin{array}{l}\mathrm{n}=1.5 \\
\delta<0.64\end{array}$ \\
\hline $1 \mathrm{~b}$ & B: 0.25 of 7 or $B *: 0.2$ of 10 & $\begin{array}{l}\mathrm{n}=0.5 \\
\delta>0.841\end{array}$ & $\begin{array}{l}\mathrm{n}=0.88 \\
\delta \text { none }\end{array}$ & $\begin{array}{l}\mathrm{n}=1.5 \\
\delta \text { none }\end{array}$ \\
\hline $2 \mathrm{a}$ & $\begin{array}{l}\text { A: } 5 \text { or } \\
A^{*}: 0.1 \text { of } 25,0.89 \text { of } 5 . \text { and } 0.01 \text { of zero }\end{array}$ & $\begin{array}{l}n=0.5 \\
\delta<0.44\end{array}$ & $\begin{array}{l}\mathrm{n}=0.88 \\
\delta<0.31\end{array}$ & $\begin{array}{l}\mathrm{n}=1.5 \\
\delta<0.22\end{array}$ \\
\hline $2 b$ & B : 0.11 of 5 or $B^{*}: 0.10$ of 25 & $\begin{array}{l}\mathrm{n}=0.5 \\
\text { none }\end{array}$ & $\begin{array}{l}\mathrm{n}=0.88 \\
\text { none }\end{array}$ & $\begin{array}{l}\mathrm{n}=1.5 \\
\text { none }\end{array}$ \\
\hline $3 a$ & $\begin{array}{l}A: 2400 \text { or } \\
A^{*}: 0.33 \text { of } 2500,0.66 \text { of } 2400 \text { and } 0.01 \text { of zero }\end{array}$ & $\begin{array}{l}\mathrm{n}=0.5 \\
\delta \text { any }\end{array}$ & $\begin{array}{l}n=0.88 \\
\delta<0.96\end{array}$ & $\begin{array}{l}n=1.5 \\
\delta<0.85\end{array}$ \\
\hline $3 b$ & B: 0.34 of 2400 or $B^{*}: 0.33$ of 2500 & $\begin{array}{l}\mathrm{n}=0.5 \\
\delta>0.74\end{array}$ & $\begin{array}{l}\mathrm{n}=0.88 \\
\delta>1.2\end{array}$ & $\begin{array}{l}\mathrm{n}=1.5 \\
\delta>1.87\end{array}$ \\
\hline
\end{tabular}

Notes; power value $G^{n}$, where $\mathrm{G}$ is gain and $\mathrm{n}$ is the constant exponent.

Weighting function $w(p)=\frac{p^{\delta}}{\left[p^{\delta}+(1-p)^{\frac{1}{\delta}}\right.}$, where $\mathrm{p}=$ probability and $\delta$ is a $\left[p^{\delta}+(1-p)^{\delta}\right]^{\frac{1}{\delta}}$

constant.

e.g in $2 \mathrm{a} \delta$ is solution of $1^{n}-\mathrm{w}(0.1) 5^{n}-[\mathrm{w}(0.99)-\mathrm{w}(0.1)] 1^{n}>0$ 
Table 2: Values of $r$ Consistent with choices in Allais and Holt and Laury Experiments for $A>A^{*}$ and $B>B$ *

\begin{tabular}{|c|c|c|c|}
\hline No. & Experiment & $\begin{array}{l}\delta=0.61 \\
\mathrm{n}=0.88\end{array}$ & $\begin{array}{l}\delta=0.95 \\
n=1.1\end{array}$ \\
\hline $1 \mathrm{a}$ & $\begin{array}{l}\text { A: } 7 \text { or } \\
A^{*}: 0.2 \text { of } 10,0.75 \text { of } 7 \text { and } 0.05 \text { of zero }\end{array}$ & r -any & $\mathrm{r}>0.0825$ \\
\hline $1 \mathrm{~b}$ & B: 0.25 of 7 or $B *: 0.2$ of 10 & $\mathrm{r}>0.28$ & $\mathrm{r}>0.1105$ \\
\hline $2 \mathrm{a}$ & $\begin{array}{l}\text { A: } 5 \text { or } \\
A^{*}: 0.1 \text { of } 25,0.89 \text { of } 5 . \text { and } 0.01 \text { of zero }\end{array}$ & $r>0.265$ & $r>0.40$ \\
\hline $2 b$ & B : 0.11 of 5 or $B^{*}: 0.10$ of 25 & $r>0.745$ & $r>0.42$ \\
\hline $3 a$ & $\begin{array}{l}A: 2400 \text { or } \\
A^{*}: 0.33 \text { of } 2500,0.66 \text { of } 2400 \text { and } 0.01 \text { of zero }\end{array}$ & $\mathrm{r}>0$ & $\mathrm{r}>0.00006$ \\
\hline $3 b$ & B: 0.34 of 2400 or $B^{*}: 0.33$ of 2500 & $\mathrm{r}>0.0051$ & $\mathrm{r}>0.00016$ \\
\hline $4 \mathrm{a}$ & A: 3000 or $A^{*}: 0.8$ of 4000 & r-any & $r>0.00007$ \\
\hline $4 \mathrm{~b}$ & B: 0.25 of 3000 or $B^{*}: 0.2$ of 4000 & $\mathrm{r}>0.00115$ & $\mathrm{r}>0.0001$ \\
\hline $5 a$ & A: 0.4 of $2,0.6$ of 1.6 or $A^{*}: 0.4$ of $3.85,0.6$ of 0.1 & r-any & r-any \\
\hline $5 b$ & B: 0.8 of $2,0.2$ of 1.6 or $B^{*}: 0.8$ of $3.85,0.2$ of 0.1 & $r>0.265$ & $\mathrm{r}>0.713$ \\
\hline $6 a$ & A: 0.4 of $40,0.6$ of 32 or $A^{*}: 0.4$ of $77,0.6$ of 2 & r-any & r-any \\
\hline $6 b$ & B: 0.8 of $40,0.2$ of 32 or $B^{*}: 0.8$ of $77,0.2$ of 2 & $r>0.02$ & $r>0.0262$ \\
\hline
\end{tabular}

Notes; expo-power value $1-\mathrm{e}^{-\mathrm{rG}} \mathrm{G}^{\mathrm{n}}$, where $\mathrm{G}$ is gain and $\mathrm{n}$ is constant exponent Weighting function $\mathrm{w}(\mathrm{p})$ as in Table1. $\delta=0.61$

e.g in $5 \mathrm{a} r$ is solution of $\left[\mathrm{w}(0.4)\left(1-\mathrm{e}^{-\mathrm{r} 2^{\mathrm{n}}}\right)+(1-\mathrm{w}(0.4))\left(1-\mathrm{e}^{-\mathrm{r} 16^{\mathrm{n}}}\right)\right]-$ $\left[\mathrm{w}(0.4)\left(1-\mathrm{e}^{-\mathrm{r} 3.85^{\mathrm{n}}}\right)+(1-\mathrm{w}(0.4))\left(1-\mathrm{e}^{-\mathrm{r} 0.1^{\mathrm{n}}}\right)\right]>0$ 
Table 3: Subjective Probabilities and Subjective Rates of Return to a 1 unit stake at various Objective Probabilities and Rates of Return

\begin{tabular}{|c|c|c|c|}
\hline No. & $\begin{array}{lr}\text { Objective } & \text { Rate of } \\
\text { Return, } \mu, & \text { and } \\
\text { Objective } & \text { win } \\
\text { probability, p. } & \end{array}$ & $\begin{array}{l}\text { Subjective Rate of Return, } \\
\mu^{\mathrm{s}}, \\
\text { Subjective win } \\
\text { Probability, w(p), } \\
\text { and Subjective loosing } \\
\text { probability, w }(1-\mathrm{p}) \text {, } \\
\text { with } \\
\delta=0.61, \\
\rho=0.69\end{array}$ & $\begin{array}{l}\text { Subjective Rate of Return, } \\
\mu^{\mathrm{s}}, \\
\text { Subjective win } \\
\text { Probability, w(p), } \\
\text { and Subjective loosing } \\
\text { probability, w }(1-p), \\
\text { with } \\
\delta=0.95, \\
\rho=0.95\end{array}$ \\
\hline 1. & $\mu=0, p=0.5$ & $\begin{array}{l}\mu^{\mathrm{s}}=-0.03348 \\
\mathrm{w}(0.5)=0.42065 \\
\mathrm{w}(1-0.5)=0.454\end{array}$ & $\begin{array}{l}\mu^{\mathrm{s}}=0 \\
\mathrm{w}(0.5)=0.49906 \\
\mathrm{w}(1-0.5)=0.49906\end{array}$ \\
\hline 2. & $\mu=0, p=0.1$ & $\begin{array}{l}\mu^{\mathrm{s}}=0.90182 \\
\mathrm{w}(0.1)=0.1863 \\
\mathrm{w}(1-0.1)=0.7749\end{array}$ & $\begin{array}{l}\mu^{s}=0.10322 \\
w(0.1)=0.11023 \\
w(1-0.5)=0.88889\end{array}$ \\
\hline 3. & $\begin{array}{l}\mu=\quad-0.052632 \\
p=\frac{1}{38}=0.026316\end{array}$ & $\begin{array}{l}\mu^{\mathrm{s}}=2.3927 \\
\mathrm{w}(0.1)=0.094035 \\
\mathrm{w}(1-0.1)=0.89853\end{array}$ & $\begin{array}{l}\mu^{\mathrm{s}}=0.1289 \\
\mathrm{w}(0.1)=0.031349 \\
\mathrm{w}(1-0.5)=0.96831\end{array}$ \\
\hline 4 & $\begin{array}{l}\mu= \\
\mathrm{p}=\frac{1}{100}=0.01\end{array}$ & $\begin{array}{l}\mu^{\mathrm{s}}=1.763 \\
\mathrm{w}(0.1)=0.055266 \\
\mathrm{w}(1-0.1)=0.94509\end{array}$ & $\begin{array}{l}\mu^{\mathrm{s}}=-0.37241 \\
\mathrm{w}(0.1)=0.012548 \\
\mathrm{w}(1-0.1)=0.98729\end{array}$ \\
\hline 5 & $\begin{array}{l}\mu= \\
p=\frac{1}{1000}=0.001\end{array}$ & $\begin{array}{l}\mu^{\mathrm{s}}=6.9469 \\
\mathrm{w}(0.1)=0.014454 \\
\mathrm{w}(1-0.1)=0.98809\end{array}$ & $\begin{array}{l}\mu^{\mathrm{s}}=-0.22346 \\
\mathrm{w}(0.1)=0.001412 \\
\mathrm{w}(1-0.1)=0.99856\end{array}$ \\
\hline
\end{tabular}

Notes; $\mu=$ po- $(1-p), \quad$ where $o$ is odds. $\quad \mu^{s}=w(p) o-w(1-p), \quad$ where $\mathrm{w}(\mathrm{p})=\frac{\mathrm{p}^{\delta}}{\left[\mathrm{p}^{\delta}+(1-\mathrm{p})^{\delta}\right]^{\frac{1}{\delta}}}, \mathrm{w}(1-\mathrm{p})=\frac{(1-\mathrm{p})^{\rho}}{\left[\mathrm{p}^{\rho}+(1-\mathrm{p})^{\rho}\right]^{\frac{1}{\rho}}}$. 